Portanto, conclui Roger Bastide, a estrutara paideumática da mística do Cosmos, que os antigos iorubas preservam até hoje na África, sobrevive entre nós na mentalidade popular brasileira.

Creio que esta visão rápida e fragmentária do pensamento estético de Roger Bastide é suficiente para que o possamos caracterizar em suas linhas gerais. Como estamos vendo, a sua meditação não gira em torno do polo racional, como costumam ser as estéticas do Ocidente; não destaca, na evolução histórica, momentos mais perfeitos de arte; não elege, como o mais alto, um determinado ideal de beleza. É sintomático aliás que, entre as manifestaçōes estéticas do passado, tenha erigido como objeto de estudo justamente o barroco, isto é, o período artístico menos afinado à sensibilidade de um francês. E que ao barroco europeu, apesar de tudo já reconhecido pela crítica, prefira a feição peculiar que este estilo de corte assume na colônia, quando o meio pobre e a mestiçagem dos artistas lhe imprimem tantas deformaçðes.

A estética de Roger Bastide é pois uma estética de antropólogo, de estudioso dos fenômenos de misticismo religioso. Mas é também uma estética de vanguarda. Na extrema mocidade Bastide passou pelo crivo do dadaísmo e do surrealismo, pelas experiências radicais que questionaram, para toda a posteridade, os valores externos da obra de arte. Era natural pois, que chegando a um pars sem grande tradição cultural, tivesse se dedicado à elaboração de uma estética pobre - usando o termo em analogia com o que hoje se costuma designar por arte pobre - isto é, uma estética que, voltando as costas para os grandes períodos e as grandes manifestaçōes artísticas, fosse desentranhar o fenômeno estético do cotidiano, dos fatos insignificantes e sem foros de grandeza, que compõem no entanto o tecido de nossa vida. Uma estética, enfim, que não se preocupando com a obra de arte - muitos menos com a obra prima - tentasse surpreender como se revelava, através de certas categorias, como o pensamento místico, uma das formas mais válidas e mais altas do conhecimento.

\title{
2. Roger Bastide e a Literatura Brasileira
}

Antonio Candido

No Brasil, Roger Bastide se interessou profundamente pela nossa arte e a nossa literatura, tornando-se um crítico militante e um estudioso que pesou de maneira notável na interpretação de fatos, idéias e obras. É preciso, portanto, começar lembrando a sua condição de colaborador freqüente dos jornais - registrando livros novos, comentando exposições, debatendo teorias e, inclusive, estabelecendo com homens do porte de Mário de Andrade e Sérgio Milliet polêmicas 
amistosas e construtivas, num exemplo de compostura e amor pela verdade que não é frequiente no gênero. Durante a II Guerra Mundial, aumentou esta participação, dizendo aos alunos e amigos que era a sua meneira de trabalhar pela presença e atuação da cultura francesa, mostrando-a empenhada nos problemas da brasileira.

Os referidos artigos, e também os estudos mais sistemáticos, eram de intuito predominantemente literário, mas quase sempre entrava neles a visão sociológica como alicerce teórico ou componente interpretativa, tornando Roger Bastide um dos poucos a usar com segurança e felicidade essa combinação difícil. $\mathbf{O}$ seu critério dominante era o intuito, sempre ressaltado nas conversas, de emitir juízos de realidade, não de valor, afastando o problema de avaliar méritos para ficar nas verificaçōes objetivas. De um lado, isso gerava certa vontade universal, principalmente com referência à produção do momento; mas, de outro, assegurava à crítica a função de análise cul tural.

Os seus artigos são numerosos e tiveram marcada influência no meio intelectual daqueles anos. Muitos foram reunidos em livro, mas na maioria estão dispersos pelos periódicos onde apareceram. Inclusive o estudo magistral sobre Machado de Assis, de que se falará adiante.

Além da produção escrita, foi grande a sua influência através do contacto direto com amigos e alunos. Eu, pessoalmente, the devo muito, e às vezes me surpreendo, relendo a anos de distância algum escrito dele, ao verificar até que ponto certas idéias que julgava minhas são na verdade, não apenas devidas à sua influência, mas já expressamente formuladas por ele. Se for permitida uma informação de cunho pessoal, contarei que a sua opinião foi decisiva para eu optar entre a sociologia e a literatura como atividade universitária. Consultei-o a propósito nos primeiros anos do decênio de 1950 e ele disse francamente que me achava mais qualificado para a segunda.

Mas muita gente melhor recebeu também a sua influência intelectual, inclusive Mário de Andrade, cujas idéias sobre a gênese da literatura popular foram certamente redefinidas graças a ela.

Não sendo possível tentar um levantamento da sua atividade com relação à literatura brasileira, indicarei nesta comunicação apenas quatro tipos de estudos, que a meu ver são importantes e cujos assuntos básicos podem ser denominados do seguinte modo:

1. incorporação dos temas do negro d poesia brasileira;

2. presença das componentes africanas no processo criador dos escritores brasileiros;

3. aculturação da literatura européia no Brasil;

4. dissociação entre o pitoresco e a idéia de "autenticidade" da literatura brasileira. 


\section{Incorporação dos temas do negro à poesia brasileira.}

A sua posição a respeito está exposta de maneira sistemática no estudo "Incorporação da poesia africana à poesia brasileira" (Poetas do Brasil, Curitiba, Guafra, 1944, p. 7-38).

Essencialmente, o intuito é pesquisar nos textos os assuntos relativos ao negro, a partir da verificação que eles são versados por poetas brancos (diríamos com maior precisão, por poetas considerados brancos e se comportando como tais). Para isto, procede a uma análise diferencial, mostrando como os referidos assuntos vão penetrando cada vez mais profundamente. Com efeito, sendo a princípio mera ocorrência temática, eles passam a suscitar a participação afetiva do poeta, em seguida provocam o aparecimento da consciéncia do drama social para, finalmente, se tornarem verdadeira incorporação no nível da forma. E nós percebemos que o seu critério central, extremamente sutil, é estudar este processo como interiorização progressiva dos traços sociais na estrutura da obra, em função das etapas da evolução histórica.

Na parte analítica, mostra que inicialmente, na literatura do perfodo colonial, o negro aparecia como elemento estranho, de fora, e o mestiço, embora considerando integrante da sociedade, como algo inferior. E ainda assim, apenas em gêneros também reputados menos nobres, sobretudo a sátira. São exceções, no fim do século XVIII, o poemeto épico Quitúbia, de Basílio da Gama, celebrando um chefe angolano fiel aos portugueses, e a referência e Henrique Dias na epopéia de Durão, Caramuru.

O século XIX e o Romantismo modificaram este estado de coisas, com a presença temática do negro em gểneros que então adquiriram a primeira plana, como a poesia lírica. A princípio, aparecendo como elemento pitoresco ou objeto de simpatia e compreensão, o que representa para Roger Bastide uma etapa menos significativa do que a seguinte, manifestada de modo superior na obra de Castro Alves. Ela se caracteriza pela consciéncia do drama social do negro, indicando passagem nítida da simpatia à revolta em face da escravidão.

Nessa incorporação que se vinha processando, a Abolição possibilitou um incremento, que é nítido nos poetas contemporâneos. A este propósito, Bastide aponta a reduplicação dos temas, mostrando como o do navio negreiro, tratado de maneira grandiloqüente por Castro Alves, reaparece em Cassiano Ricardo despojado de retórica, reduzido ao essencial, como experiência do poeta e não como assunto a ser desenvolvido. No mesmo sentido analisa o tratamento, por Jorge de Lima, do tema castroalvino dos Palmares. Em tais casos, verifica-se a entrada do espírito da poesia dos africanos na técnica poética; e o que era social se torna a própria essência do fazer: incorporação dos ritmos de marcha, de tambor, de canto, em substituição, ou ao lado dos ritmos eruditos. 


\section{Presença das componentes africanas no processo criador dos escritores brasileiros.}

A "Introdução" d' A poesia afro-brasileira (São Paulo, Martins, 1943, p. 7-15) constitui a exposição sistemática deste tema, que aliás se difunde por todo o livro, cujo material é formado pela obra dos poetas considerados mestiços e negros, ao contrário do anteriormente citado, que estuda, como vimos, os poetas considerados brancos.

$\mathrm{O}$ intuito é verificar de que maneira a origem racial e a condição social decorrente interferem na elaboração das obras. Partindo das referências meramente temáticas para chegar às impregnaçð̃es mais sutis da forma, Bastide trabalha numa gama extensa, procurando captar esta passagem difícil. Mas as dificuldades não o intimidam, e ele põe em jogo a sutileza costumeira e o senso de profundidade, para aferir o papel dos elementos inconscientes e o condicionamento da forma pelas origens do escritor.

O seu ponto de partida é a conviç̧ão de que a origem racial dá lugar a formação de certos traços profundos da personalidade literária, que escapam à consciência mas interferem decisivamente na criação. Entretanto, a sua pesquisa não se orienta pela psicanálise, pois não se trata de libido nem das fixações infantis recalcadas, embora elas possam ser levadas em conta. Interessa-lhe a atuação de elementos sociais e psíquicos condicionados pela raça e comprováveis pelo conhecimento da biografia ostensiva e da sociedade.

A hipótese de trabalho é que a aparência "ocidental" de um texto não deve enganar quanto às impregnações profundas, pois ela pode recobrir, e quase sempre recobre, a atuação de fixações devidas à origem racial e à condição social derivada, sendo preciso levá-las em conta para entender o escritor.

Com este roteiro teórico estuda diversos autores, maiores e menores; mas a realização mais cabal são os "Quatro estudos sobre Cruz e Sousa", ainda hoje os mais importante a respeito do poeta e verdadeiros clássicos da nossa crítica. Eles se baseiam em análises e interpretações refinadas sobre a cor, a luz, os cabelos na imagética e no temário, mostrando como manifestavam componentes pessoais de fundo africano. Através da leitura em profundidade, o racial, o social e o estético são apresentados pelo crítico na coesão de uma fatura poética peculiar e permitem a reavaliação do poeta, que ele associa a Mallarmé e a Stefan George para formar uma espécie de tríade simbolista.

\section{Aculturação da literatura européia no Brasil.}

Este problema foi tratado de maneira menos desenvolvida que os anteriores, mas aparece em diversos escritos. Assim, é referido de passagem nos capítulos I, II e III de A poesia afro-brasileira e enforma parte do curso mimeografado do 
Instituto de Altos Estudos da América Latina: Etudes de Littérature Brésilienne (1955). A formulação sistemática se encontra no artigo "Sociologie et Littérature Comparée", publicado em Cahiers Internationaux de Sociologie, XVII, 1955, p. 93-100, reproduzido sob o título "L'Acculturation Littéraire", com o título anterior como subtítulo, no livro Le Prochain et le Lointain, Paris, Cujas, 1970, p. 201-209.

Nele, propõe uma revisão conceitual das chamadas influências de uma literatura sobre outra, à luz dos pontos de vista da Sociologia e da Antropologia, mostrando que nunca se verifica o fato puro e simples da cópia, porque os traços são sempre redefinidos. A propósito, efetua uma revalorização de Tarde, indicando a importância da sua teoria da imitação para o estudo de problemias deste tipo. Dar, parte para uma crítica da Antropologia Cultural à luz da Sociologia, assinalando que o fenômeno da difusão não é apenas cultural, mas também social, devendo-se levar em conta a natureza dos contextos para uma compreensão adequada.

Estribado neste critério, faz algumas observaçoes importantes sobre a nossa literatura, lembrando, por exemplo, que é errado encarar o movimento arcádico como "imitação servil", ou transposição artificial da moda européia. Com efeito, histórica e sociologicamente, ele assume - através da adoção de formas cultas e requintadas, elaboradas noutro contexto - a funçăo de afirmar a capacidade do intelectual da Colónia e, por extensão, a de toda a Colónia. Tanto assim, observa Bastide, que esses éscritores supostamente artificiais e desligados da realidade, devido a uma imitação aparentemente mecânica, são, na verdade, os mesmos que se envolvem no projeto político da Inconfidência.

Igualmente fecunda é a sua visão do Indianismo romântico enquanto recurso ideológico da classe média em formação, na qual se encaixou o mestiço, e que teve por isso necessidade de elaborar uma noção compensatória, descartando a mestiçagem com o negro (elemento servil do momento) por meio da valorização da mestiçagem com o indio, que a podia substituir como disfarce. Deste modo, apesar da origem francesa, o Indianismo, visto do angulo da sua função social, foi redefinido e se tornou algo "necessário" na sociedade brasileira.

Muito brilhante é o estudo, feito do mesmo ângulo, sobre o uso por Castro Alves da antítese como recurso de composição, não mera figura poética. Ê certo que ele a tomou de Victor Hugo, mas no Brasil ela assumiu outra dimensão, pois a sociedade local se caracterizava por certas grandes antíteses sociais, cuja existência lhe deram nova funcionalidade: Independência X Escravidão; Senhor branco X Escravo negro. Daf a possibilidade de um funcionamento peculiar, de significado diverso e sociologicamente muito mais relevante, que afasta a idéia de "imitação mecânica".

Outro caso é o do Barroco, igualmente redefinido e transformado em via de expressão do mulato, e que Bastide focaliza em termos que coincidem essencialmente com a famosa análise de Mário de Andrade, no estudo sobre o Aleijadinho. 


\section{Dissociação entre o pitoresco e a idéia de "autenticidade" da literatura brasileira.}

Mais um caso de afinidade com Mário de Andrade, talvez configurando certa inter-influência dos dois autores, pode ser encontrado no ensaio que a meu ver é a maior contribuição de Roger Bastide aos estudos de literatura brasileira: "Machado de Assis, paisagista", Revista do Brasil, 3ạ Fase, nọ 29, novembro de 1940, p. 3-14.

É um artigo capital, que nos influenciou decisivamente e marcou uma reorientação na maneira de conceber certos aspectos fundamentais da nossa literatura. Influência tanto maior quanto a idéia central do artigo era uma dessas convicções que Roger Bastide sabia cultivar com paciência obstinada e suave firmeza, repetindo-a freqüentemente nas aulas, nas conversas, nos debates, e que pode ser expressa do seguinte modo: ao contrário do que se diz, o cunho de "autenticidade" da literatura brasileira não depende da descrição ostensiva de traços característicos do país. O descritivismo, a presença indiscreta da paisagem e dos tipos exóticos, podem constituir, ao contrário, visão externa, ponto de vista de estrangeiro, e não compreensão profunda e autêntica.

Estudando Machado de Assis, Bastide elabora uma espécie de paradoxo metódico, ou estratégico, provando que nele a paisagem está presente com grande força, ao contrário do que sempre se afirmou; só que na filigrana, tão intimamente entrosada com a caracterização e a condução do enredo, que não fere a atenção do leitor. Interiorizada, incorporada à estrutura narrativa, ela é muito mais "necessária" do que nos escritores paisagistas, indiscretos no abuso das "pintuas", prejudicando a narração pela descrição. Assim, seria possível dizer, como ele nos dizia em aulas e conversas, que Machado de Assis podia até ser considerado "mais brasileiro" do que, por exemplo, Alencar ou Euclides da Cunha, porque nele a paisagem do Brasil se torna algo essencial à economia profunda da obra, insinua-se no gesto do personagem, na fisionomia, no sentimento, na ação, como uma espécie de presença virtual.

Este artigo decisivo convergiu com a longa argumentação desenvolvida mais ou menos no mesmo sentido por Mário de Andrade desde o decênio de 1920. E, de certo modo, disse a palavra final, na medida em que demonstrou por meio de um caso aparentemente indemonstrável, - como é o do comedido, introvertido Machado de Assis.

Os exemplos indicados tencionam dar uma idéia da grande contribuição de Roger Bastide para os estudos sobre a literatura brasileira. Ao mesmo tempo, ficaram sugeridas.algumas das suas posições no campo da Sociologia da Arte e da Literatura, sistematizadas no livro Arte e Sociedade, constituído pela matéria dos seus cursos de 1939 e 1940 (São Paulo, Martins, 1945). 
Trata-se de um tratamento objetivo dos fatos artísticos, que leva em conta o condicionamento social e a atuaça da arte sobre a sociedade, mas evita a rigidez dos determinismos. Isto porque se mostra igualmente atento a "vida das formas", à sua dinâmica própria, e quebra a idéia de causalidade unilateral. Esta flexibilidade' e abertura do pensamento de Bastide lhe permitiu a posição compreensiva com que analisou os fatos da literatura brasileira, indicando o seu interrelacionamento com a sociedade e a cultura e procurando mostrar a tradução estética dos fatores "externos".

\section{Sobre a contribuição de Roger Bastide à Psicologia Social}

Virgínia Leone Bicudo

A oportunidade desta reunião, para pussarmos o pensamento de Roger Bastide, não é somente demonstração de sua presença entre nós, mas é também uma forma de retomar contato com suas contribuições no campo da psicologia social.

Em 1948, Bastide publicava "Sociologia e Psicanálise", em cujo livro se reflete a personalidade de um sociólogo capaz de sobrepor-se a preconceitos, particularmente ao preconceito científico. Da primeira à última página de seu livro confronta teorias sociológicas com teorias psicanalíticas, como se estivesse dialogando com os respectivos autores, ora assumindo a posição de um, ora a de contestador, para finalmente colocar seu ponto de vista.

A dúvida, que lhe permitia um constante questionar, nos favorece a prosseguirmos em diálogo com Roger Bastide, sobre as contribuiçðes recíprocas entre a psicanálise e a psicologia social, esta última constituindo-se em um elo entre a psicologia e a sociologia. Esta posição surge explicitada em "Sociologia e Psicanálise" nos termos: "No decorrer de nosso estudo, uma inversão total se operou. Pensávamos a princípio que era o indivíduo que se explicava pela sociedade; na realidade, porém, esta sociedade atual tem uma história, um começo; e fazendo sociologia genética percebemos que é o indivíduo que explica o social. Em suma, a psicanálise, parecendo a princípio postular a sociologia, acaba por inverter a sociologia clássica e substituí-la por outra completamente diversa. Esta nova sociologia é do tipo psicológico, pois que o social remonta ao psíquico. Distingue-se das outras do mesmo tipo por tratar-se de um psiquismo de natureza libidinosa". (pg. 178-9)

Com o evoluir da psicanálise e das ciências sociais, cada vez mais a posição de Roger Bastide vem se confirmando. Se com Freud a ênfase na abordagem do fato psíquico recai sobre os instintos e suas vicissitudes, com Melanie Klein a 